\section{Dinucleotide repeat polymorphism at the D18S34 locus}

\author{
James L.Weber* and Paula E.May \\ Marshfield Medical Research Foundation, 510 \\ North St Joseph Avenue, Marshfield, WI 54449, \\ USA
}

Source/Description: A human genomic AluI fragment was cloned into $\mathrm{mp} 10$ and selected by hybridization to poly $(\mathrm{dC}-\mathrm{dA}) \cdot \operatorname{poly}(\mathrm{dG}-$ dT). The cloned fragment was designated Mfd26. Sequencing of Mfd26 provided the information necessary for polymerase chain reaction primer synthesis. The clone length was $223 \mathrm{bp}$, and the predicted length of the amplified fragment was $115 \mathrm{bp}$.

Primer sequences: CAGAAAATTCTCTCTGGCTA (CA strand); CTCATGTTCCTGGCAAGAAT (GT strand).

Frequency: Estimated from 108 chromosomes of unrelated CEPH family grandparents (Caucasians). PIC $=0.78$.

$\begin{array}{llll}\text { Allele (bp) } & \text { Frequency } & \text { Allele (bp) } & \text { Frequency } \\ 119 & 0.01 & 109 & 0.20 \\ 117 & 0.03 & 107 & 0.06 \\ 115 & 0.07 & 105 & 0.11 \\ 113 & 0.28 & 103 & 0.01 \\ 111 & 0.22 & & \end{array}$

Chromosomal Localization: Assigned to chromosome 18 using DNA templates isolated from panels of somatic cell hybrids.

Mendelian Inheritance: Co-dominant segregation was observed in 15 two generation families.

Other Comments: Conditions for the amplification reactions were as described in the reference except that samples were processed through 27 temperature cycles consisting of $1 \mathrm{~min}$ at $94^{\circ}, 2 \mathrm{~min}$ at $55^{\circ}$ and $2 \mathrm{~min}$ at $72^{\circ}$. Sizes of the alleles were determined by comparison to mp8 DNA sequencing ladders and were the averages of the sizes of the GT-strand and CA-strand bands. The dinucleotide repeat sequence in $\mathrm{Mfd} 26$ was of the form $(\mathrm{AC})_{28} \mathrm{~A}$. The sequence of $\mathrm{Mfd} 26$ has been submitted to GenBank.

Acknowledgements: This work was supported by the Marshfield Clinic and NIH grant GM41773.

Reference: Weber,J.L. and May,P.E. (1989) Am. J. Hum. Genet. 44, 388-396.

\section{Dinucleotide repeat polymorphism at the D3S240 locus}

\author{
James L.Weber* and Paula E.May \\ Marshfield Medical Research Foundation, 510 \\ North St Joseph Avenue, Marshfield, WI 54449, \\ USA
}

Source/Description: A human genomic AluI fragment was cloned into $\mathrm{mp} 10$ and selected by hybridization to poly $(\mathrm{dC}-\mathrm{dA}) \cdot \operatorname{poly}(\mathrm{dG}-$ $\mathrm{dT})$. The cloned fragment was designated Mfd30. Sequencing of Mfd30 provided the information necessary for polymerase chain reaction primer synthesis. The clone length was $221 \mathrm{bp}$, and the predicted length of the amplified fragment was $92 \mathrm{bp}$.

Primer sequences: CCATGTCCCATATCTCTACA (CA strand); TGAAATCACTGATGACAATG (GT strand).

Frequency: Estimated from 122 chromosomes of unrelated $\mathrm{CEPH}$ family grandparents (Caucasians). PIC $=0.30$.

Allele (bp) Frequency Allele (bp) Frequency

$\begin{array}{llll}99 & 0.01 & 91 & 0.02\end{array}$

$\begin{array}{llll}97 & 0.08 & 89 & 0.01\end{array}$

$\begin{array}{llll}95 & 0.01 & 87 & 0.82\end{array}$

$\begin{array}{llll}93 & 0.01 & 83 & 0.04\end{array}$

Chromosomal Localization: Assigned to chromosome 3 using DNA templates isolated from panels of somatic cell hybrids.

Mendelian Inheritance: Co-dominant segregation was observed in 15 two generation families.

Other Comments: Conditions for the amplification reactions were as described in the reference except that samples were processed through 27 temperature cycles consisting of $1 \mathrm{~min}$ at $94^{\circ}, 2 \mathrm{~min}$ at $55^{\circ}$ and $2 \mathrm{~min}$ at $72^{\circ}$. Sizes of the alleles were determined by comparison to mp8 DNA sequencing ladders and were the averages of the sizes of the GT-strand and CA-strand bands. The dinucleotide repeat sequence in $\mathrm{Mfd} 30$ was of the form $(\mathrm{AC})_{18} \mathrm{~A}$. The sequence of $\mathrm{Mfd} 30$ has been submitted to GenBank.

Acknowledgements: This work was supported by the Marshfield Clinic and NIH grant GM41773.

Reference: Weber,J.L. and May,P.E. (1989) Am. J. Hum. Genet. 44, 388-396.

\footnotetext{
* To whom correspondence should be addressed 